\title{
DAREMOS AO MUNDO O "HOMEM CORDIAL": AS REPRESENTAÇÕES SOBRE O BRASIL NOS LIVROS DIDÁTICOS DE HISTÓRIA DO BRASIL E HISTÓRIA DA AMÉRICA DE JOAQUIM SILVA
}

\author{
Felipe Augusto dos Santos Vaz \\ Universidade Federal de São Paulo, Brasil \\ fevaz18@gmail.com
}

\begin{abstract}
RESUMO: Objetos culturais que carregam consigo determinadas representações da realidade, os livros didáticos são elaborados com vistas a ratificar certas memórias, fomentando o complexo jogo de tensões estabelecido no campo social. Servindo como importante ferramenta de construção da cultura e da identidade nacional brasileira, muitas obras didáticas apresentaram em seus conteúdos as especificidades de nosso caráter nacional. Em face a estas questões, a pesquisa que ora se apresenta busca evidenciar determinadas representações sobre o Brasil nos livros História do Brasil: para a primeira série ginasial e História da América para a segunda série do ginasial, de Joaquim Silva, com o intuito de perceber como tais objetos podem ser interpretados como importantes instrumentos que legitimam, no caso brasileiro, a ideia do homem cordial.
\end{abstract}

Palavras-chave: Representação, homem cordial, manuais escolares, lugar de memória.

\section{DAREMOS AL MUNDO EL "HOMBRE CORDIAL": LAS REPRESENTACIONES SOBRE BRASIL EN LOS LIBROS DIDÁCTICOS DE HISTORIA DE BRASIL E HISTORIA DE AMÉRICA DE JOAQUIM SILVA}

RESUMEN: Objetos culturales que Ilevan consigo ciertas representaciones de la realidad, los libros didácticos son elaborados con miras a ratificar ciertas memorias y, alentando el complejo juego de tensiones establecido en el campo social. Sirviendo como importante herramienta de construcción de la cultura y de la identidad nacional brasileña, muchas obras didácticas presentaron en 
sus contenidos las especificidades de nuestro carácter nacional. En el marco de estas cuestiones, la investigación que ahora se presenta busca evidenciar determinadas representaciones sobre Brasil en los libros História do Brasil: para a primeira série ginasial e História da América para a segunda série do ginasial, de Joaquim Silva, con el propósito de percibir cómo tales objetos pueden ser interpretados como importantes instrumentos que legitiman, en el caso brasileño, la idea del hombre cordial.

Palabras clave: representación, hombre cordial, manuales escolares, lugar de memoria.

Recibido: 20 de abril de 2019

Aceptado: 14 de mayo de 2019

\section{Introdução}

Objetos de cultura resultantes de um campo ${ }^{1}$ em conflito, os livros didáticos se constituem como produtos complexos e multifacetados, cuja produção se caracteriza por uma série de fatores como as disputas de narrativas ${ }^{2}$, os mecanismos de apropriação ${ }^{3}$ e as relações e lugares de poder $^{4}-\mathrm{e}$, dessa forma, consistem em importantes veículos que propagam certos modelos culturais, fundamentados por determinadas representações ${ }^{5}$ da realidade vivida.

Dispositivos que servem a distintos interesses, as obras didáticas surgiram, simultaneamente, à formação dos Estados Nacionais no decorrer do século XIX -atuando como verdadeiros instrumentos de disseminação e consolidação do sentimento nacionalista. No caso brasileiro, a situação não se esquadrinhara de maneira diferente, uma vez que tais materiais se tornaram um dos principais

1. A compreensão de campo, referido por esta pesquisa, se orienta pelas considerações cunhadas por Pierre Bourdieu, entendendo-o, portanto, como um microcosmo, um espaço simbólico em constante conflito. (Bourdieu, P., "Algumas propriedades dos campos", P. Bourdieu, Questões de sociologia. Rio de Janeiro 1983).

2. Disputas que, na lógica de Christian Laville, resultam nas "guerras de narrativas": Laville, C., A guerra das narrativas: debates e ilusões em torno do ensino de História. Revista Brasileira de História 19 (1999), pp. 125-138.

3. Chartier, R., "A história cultural entre práticas e representações", Lisboa 2002.

4. A investigação que ora se apresenta compreende como "lugares de poder" determinados espaços instituídos dentro de um campo sociocultural, cujos agentes detêm posicionamentos que o tornam detentores do capital cultural. Esses espaços, por sua vez, relacionam-se -muitas vezes através de situações conflitantes -, traçando, assim, as disputas desencadeadas naquele campo. Ver: Bourdieu, P., "O poder simbólico". Lisboa 1989, pp. 133-161.

5. Este trabalho entende por representação o processo de construção de sentidos, no qual os discursos tendem a apreender, estruturar e moldar o mundo. (Chartier, R., op. cit., 2002). 
vetores à manutenção de nossa cultura- difundindo, assim, modos específicos de pensar o país.

Decerto, estas formas de reflexão se encontram intrinsicamente coordenadas por determinados projetos de ordenação da identidade nacional que, por sua vez, se promove e se legitima como uma "construção simbólica" consubstanciada por certos sujeitos que, a partir de seu lugar de poder, intentam obter o "(...) monopólio da definição sobre o Ser nacional6". Ainda, não seria demais salientar que este "Ser nacional" leva em conta uma série de características dentre as quais uma noção básica se faz evidente nesta pesquisa: a ideia de uma suposta homogeneidade, cujo discurso uniformizante acaba por apagar os conflitos sociais e garantir o espírito coletivo almejado.

Pensando, novamente, no caso do Brasil, este processo de obliteração das contrariedades e adversidades foi ensejado por diversos intelectuais ao longo do tempo. Atentando-nos, especificamente, sobre o início dos anos 30, a construção de nosso nacionalismo entraria numa nova fase. O desenvolvimento de novas concepções e teorias trazia à tona formas inovadoras de compreensão do social, que, dessa forma, se pautara na promoção de um revisionismo dos aspectos que até então havia se ratificado -sobretudo, quanto à questão das narrativas acerca da homogeneidade do povo.

Nestas circunstâncias, teve-se forjado o conceito do "homem cordial" -tomado como sentimento capital de nossa índole, característica básica do caráter nacional. Engendrado por Ribeiro Couto, a cordialidade- em seu "(...) sentido exato e estritamente etimológico $(. . .)^{7 \prime \prime}$-enraizou-se nas estruturas mentais do povo brasileiro, norteando novas formas de leitura de um país, acentuadamente, marcado pela heterogeneidade e cujo processo histórico fora- e ainda o é -marcadamente violento.

Em vista de tais argumentos, as reflexões articuladas nas páginas que se seguem tencionam evidenciar determinadas representações sobre a sociedade brasileira em alguns manuais escolares de História do Brasil e História da América com o intuito de compreender o que as narrativas destes materiais nos têm a dizer sobre a questão da imaginada cordialidade do povo brasileiro. Posto isso, opta por debruçar sobre as obras História do Brasil: para a primeira série ginasial e a História da América para a segunda série do ginasial, escritas por Joaquim Silva e publicados na década de 1950 sob o selo da Companhia Editora Nacional -uma das mais importantes casas editoriais do século XX.

Para tal, na primeira seção, tem-se apresentadas as historicidades ligadas à construção conceitual do "homem cordial". Apontando a definição proposta por Ribeiro Couto e percebendo sua imprescindibilidade às narrativas emprega-

6. Ortiz, R., "Cultura Brasileira e Identidade Nacional". São Paulo 1985, p. 9.

7. Buarque de Holanda, S., "Raízes do Brasil". São Paulo 2014, p. 240. 
das na construção da identidade nacional brasileira, torna-se essencial destacar como o conceito em questão fora absorvido e, no mais das vezes, retrabalhado por intelectuais como Gilberto Freyre e Sérgio Buarque de Holanda -incorporando, consciente ou inconscientemente, as pretensões políticas em voga.

Em seguida, propõe-se uma breve exposição referente aos livros didáticos, com o intuito de se fazer perceber as dimensões que demarcam seu processo produtivo - destacando, assim, a importância da criação das representações; sua função didático-pedagógica; e, naqueles voltados à história como disciplina escolar, sua capacidade de mobilizar um importante conjunto de memórias, bem como seu valor frente aos projetos empregados nas tentativas de formação do sentimento nacionalista.

À posteriori, no terceiro segmento, serão tecidas algumas ponderações realizadas a partir das análises sobre as fontes aqui contempladas. Buscando, dentre outras coisas, frisar os aspectos gerais que constituem as obras, são apresentadas certas discussões a respeito dos discursos historiográficos que estes manuais se propõem a difundir; a ordenação proposta para os conteúdos; a relação estabelecida entre texto e iconografia -na construção, ou não, das narrativas pretendidas-; assim como a exposição de determinados trechos que exemplifiquem os aspectos ligados às intencionalidades de uma identidade nacional demarcada fortemente pelo caráter cordial.

\section{A construção histórica da cordialidade brasileira}

A década de 1930 pauta-se como um significativo marco às mudanças sociais assistidas no Brasil. Na verdade, tais transformações já vinham se esquadrinhando desde os primeiros decênios do século XX, com os impactos da Belle-Époque. A contínua busca pelo progresso e modernização do país -que, até então, se restringia à capital e a metrópole paulista- trouxera à tona o aceleramento do processo de urbanização e industrialização; a difusão do rádio; o telégrafo; o bonde e tantos outros elementos técnicos e tecnológicos tomados como símbolos da modernidade ${ }^{8}$.

Nesta conjuntura, a percepção acerca da cultura nacional e, portanto, da identidade brasileira, também passaria a adquirir novas conformações. Anteriormente, fortemente pautado pelas teorias racialistas - desenvolvidas no Brasil desde o século XIX-, o projeto de formação do nacionalismo apresentava ambiguidades e profundas lacunas que classificavam e excluíam grande parte dos sujeitos. Mas, na incessante busca pela transformação radical do conceito do homem brasileiro ${ }^{9}$-assistido na década de 1930-, as teorias até então em

8. Ortiz, R., op. cit., 1985.

9. Ibid., p. 42. 
voga se tornaram, cada vez mais, obsoletas e descompassadas à nova realidade social, desencadeando uma significativa reestruturação das narrativas e uma reconstrução do imaginário da nação -ambos, marcados pela incorporação de novos elementos aos discursos interpretativos sobre o Brasil: dentre eles, a cordialidade ${ }^{10}$.

Cunhado, em 1931, por Ribeiro Couto, o conceito em questão fora absorvido e reanalisado por diferentes intelectuais ao longo do tempo -respaldando as novas considerações ligadas à brasilidade. Em conversa com Alfonso Reyes, Couto chamara atenção aos sujeitos envolvidos e aos acontecimentos ligados à formação dos valores inerentes ao sujeito latino americano, apreciado como um verdadeiro "homem cordial":

É da fusão do homem ibérico com a terra nova e as raças primitivas, que deve sair o 'sentido americano' (latino), a raça nova produto de uma cultura e de uma intuição virgem -o Homem Cordial. (...) O egoísmo europeu, batido de perseguições religiosas e de catástrofes econômicas, tocado pela intolerância e pela fome, atravessou os mares e fundou ali, no leito das mulheres primitivas e em toda a vastidão generosa daquela terra, a Família dos Homens Cordiais, esses que se distinguem do resto da humanidade por duas características essencialmente americanas: o espírito hospitaleiro e a tendência à credulidade. Numa palavra, o Homem Cordial ${ }^{11}$.

Levando em consideração a natureza egoísta do elemento europeu e as consequências desta índole, Ribeiro Couto combinara conceitos como raça e cultura, despontando-se como um dos poucos intelectuais a levar em conta -até aquele momento-, os aspectos positivos da miscigenação. Moldando, portanto, os princípios inatos do homem latino americano e evidenciando sua distinção em relação ao resto da humanidade, tomara-o como símbolo do espírito hospitaleiro e da credulidade -projetando e justificando as particularidades das relações sociais estabelecidas desde o século XVI.

Tais noções encontraram condições propícias ao seu enraizamento no terreno fértil dos estudos voltados à compreensão do povo e da identidade nacional brasileira. As reflexões de Gilberto Freyre, defendidas nas páginas de Casa-grande \& senzala: introdução à história da sociedade patriarcal no Brasil, constituem um significativo exemplo. Tomado, por muitos intelectuais, como pioneiro às

10. Deve-se ressaltar que essa busca pela compreensão do que seria o brasileiro, assistida com o alvorecer dos anos 1930, apresentava também um sistema de classificação e exclusão. Entretanto, em comparação aos discursos produzidos anteriormente, as considerações tecidas pelos intelectuais no decorrer do período varguista, de certa forma, adquiriram uma nova conformação, integrando sujeitos outrora completamente excluídos.

11. Bezerra, E. "Ribeiro Couto e o homem cordial". São Paulo 2005. 
novas formas de interpretação do caráter nacional, o sociólogo pernambucano ambicionou "(...) tornar-se o autor do primeiro grande trabalho de cunho sociológico que consiga romper com o racismo que caracterizava boa parte de nossa produção erudita sobre o assunto (... $)^{12 \prime \prime}$, expondo argumentos que apontavam o fator cultural como definidor da identidade nacional -e não o racial, como até então sustentavam as teorias.

Voltando-se ao nosso passado colonial e buscando apresentar os costumes religiosos; os comportamentos sexuais; os aspectos delineadores da linguagem e outras práticas cotidianas, Gilberto tencionava traçar a origem das propriedades culturais de seu Brasil contemporâneo, analisando, para isso, os resquícios deixados pelo modelo familiar patriarcal estruturado ao longo da colonização empreendida pelos portugueses. Orientando suas perspectivas através do processo de miscigenação -tomado como prática fundamental à formação da sociedade-, apontara:

Híbrida desde o início, a sociedade brasileira é de todas da América que se constituiu mais harmoniosamente quanto às relações de raça: dentro de um ambiente de quase reciprocidade cultural que resultou no máximo de aproveitamento dos valores e experiências dos povos atrasados pelo adiantado ${ }^{13}$.

Logo, inseridos numa relação harmoniosa, brancos, negros e indígenas se miscigenariam -não apenas biologicamente, mas, sobretudo, culturalmente- e, em consequência, estruturariam os pormenores determinantes ao Ser nacional. Dessa forma, pauta-se que sob sua ótica o "mestiço" viria adquirir novas roupagens $^{14}$ :

A ideologia da mestiçagem, que estava aprisionada nas ambuiguidades das teorias racistas, ao ser reelaborada pode difundir-se socialmente e se tornar senso comum, ritualmente celebrado nas relações do cotidiano, ou nos grandes eventos como o carnaval e o futebol. O que era mestiço torna-se nacional ${ }^{15}$.

A lógica construída por Freyre assentou as bases da chamada "democracia racial ${ }^{16 "}$. Demarcada pela relação cordial estabelecida entre sujeitos racialmen-

12. Benzaquen de Araújo, R., "Guerra e paz: Casa-Grande \& Senzala e a obra de Gilberto Freyre nos anos 30". Rio de Janeiro 2014, p. 28.

13. Freyre, G., "Casa Grande \& Senzala: introdução à história da sociedade patriarcal no Brasil". Rio de Janeiro 1995, p. 160.

14. Ortiz, R. "Cultura Brasileira e Identidade Nacional". São Paulo 1985.

15. Ibid., p. 41.

16. Deve-se pontuar que o termo em questão não se encontra inserido nas páginas de sua Casa-Grande \& Senzala. 
te distintos, tal raciocínio buscava mostrar que, na história do país, inexistiam quaisquer conflitos e preconceitos -apontando, assim, um sentimento de nostalgia e saudosismo em relação ao nosso passado colonial. A noção de cordialidade, determinante às relações em questão, definia-se pela polidez dos indivíduos, pautada pela necessidade de se estabelecer vínculos afetivos entre $\mathrm{si}^{17}$. Porém, esse sentimento teria origem na relação hierárquica estabelecida entre senhores e escravos- "(...) estaria afeito ao mandonismo e ao personalismo, vivendo na esfera pública as relações privadas $(. . .)^{18 \prime \prime}$. Neste sentido, pode-se dizer que

...a 'cordialidade' para Freyre surge das relações de equilíbrio entre as realidades tradicionais e profundas, entre o sadismo e o masoquismo, entre os senhores e os escravos; até porque a partir dessas relações é que surgem a espontaneidade, a imaginação e as emoções. Nestas relações harmoniosas o autoritarismo e as preferências pessoais reinam sobre o gozo do mando ${ }^{19}$.

Enquadrado no mesmo cenário, outro intelectual cujos estudos se tornaram indispensáveis às interpretações sobre o Brasil fora Sérgio Buarque de Holanda -que, em 1936, publicara o seu Raízes do Brasi20 ${ }^{20}$. Debruçando-se, com maior afinco sobre a problemática relação entre público e privado estabelecida na história do país, Holanda propunha um novo sentido à cordialidade- esse "traço definido do caráter brasileiro ${ }^{21 "}$. Evocando as colocações de Ribeiro Couto, iniciara a discussão:

Já se disse, numa expressão feliz, que a contribuição brasileira para a civilização será de cordialidade-daremos ao mundo o 'homem cordial'. A Ihaneza no trato, a hospitalidade, a generosidade, virtudes tão gabadas por estrangeiros que nos visitam, representam, com efeito, um traço definido do caráter brasileiro, na medida, ao menos, em que permanece ativa e fecunda a influência ancestral dos padrões de convívio humano, informados no meio rural e patriarcal22.

17. A ideia de "polidez" em Gilberto Freyre não se assemelha àquela discutida por Sérgio Buarque de Holanda, em Raízes do Brasil. Ver: Gonçalves Marçola, F. "O que é cordialidade? O conceito de cordialidade em Sérgio Buarque de Holanda e Gilberto Freyre". Paraná 2005.

18. Ibid., p. 9.

19. Ibid., p. 47.

20. A pesquisa realizada por Júlia Matos demonstra que ao produzir o seu Raízes do Brasil, Sérgio Buarque de Holanda "Não se propôs fazer um livro de História, mas uma obra que dialogasse com seu tempo e problemas sociais, fazendo, assim, uma história do tempo presente", buscando compreender tal psicologia. Ver: Matos, J., "Tradição e modernidade na obra de Sérgio Buarque de Holanda". Biblos 17 (2005), pp. 131-143.

21. Buarque de Holanda, S., "Raízes do Brasil". São Paulo (2014), p. 176.

22. Ibid., p. 176. 
Interpretada como uma herança patriarcal da colonização portuguesa, a cordialidade em Sérgio Buarque se contrapunha àquela apontada por Freyre. Contrariando a ideia de um sentimento estabelecido por conta dos moldes hierárquicos sociais, as reflexões de Holanda destacavam que o modo de agir do homem cordial detinha origem no seio familiar. Longe de ser um sujeito imbuído de boas maneiras ou civilidade -equivalendo, assim, a um indivíduo polido, fortemente demarcado pela expressão ritualística de respeito-, o homem cordial configurava-se por "(...) um fundo emotivo extremamente rico e transbordante (... $)^{23 \prime \prime}$, definindo-se, assim, por seu "(...) passionalismo, personalismo, irreverência em face de normas institucionais, nunca submissão ${ }^{24 \prime}$-conforme assinalado em Casa-Grande \& Senzala.

As reflexões de Sérgio Buarque de Holanda ora se aproximavam, ora se afastavam dos estudos de Gilberto Freyre. Decerto, concordavam quanto a existência do caráter cordial do brasileiro e mesmo de seus reflexos sobre a relação entre o público e o privado -no qual este prevalecia sobre aquele-, mas dissentiam-se, profundamente, quanto ao modo de enxergar as direções a serem tomadas quanto à existência dessa personalidade:

...o sentido do conceito em Sérgio Buarque é de negatividade e lamentação, cordialidade é percebida como um entrave e que deveria ser superada; enquanto para Gilberto Freyre o sentido do conceito é de positividade e exaltação, cordialidade é percebida como uma característica peculiar da sociedade brasileira e que deveria ser preservada ${ }^{25}$.

Independentemente dos fundamentos empregados, a noção de cordialidade aprofundou-se no inconsciente coletivo e moldou as formas interpretativas sobre nossa sociedade. Servindo como respaldo às intencionalidades estruturantes de nosso nacionalismo, a ideia do homem cordial ratificara o processo de obscurecimento das incompatibilidades; de apagamento dos conflitos sociais. Nesse bojo, as perspectivas negativas de Sérgio Buarque não encontrariam tamanha aceitação como as ponderações levantadas por Gilberto Freyre -que,

23. Ibid., p. 176.

24. Vainfas, R. "O imbróglio de Raízes: notas sobre a fortuna crítica da obra de Sérgio Buarque de Holanda". Revista Brasileira de História 36 (2016), p. 4. Para Além, Fernanda Marçola destaca que esse homem cordial, "(...) desejoso de estabelecer relações de intimidade, não é cerimonioso, age através impulsos afetivos, tem horror às distâncias, quer tornar todas relações pessoais, não aceita ordens ou normas e leis coletivas". (Gonçalves Marçola, F. "O que é cordialidade? O conceito de cordialidade em Sérgio Buarque de Holanda e Gilberto Freyre". Paraná 2005).

25. Gonçalves Marçola, F. "O que é cordialidade? O conceito de cordialidade em Sérgio Buarque de Holanda e Gilberto Freyre". Paraná 2005, p. 49. 
como pôde ser visto, difundira a imagem de um verdadeiro "paraíso racial26" e, portanto, um Estado genuinamente civilizado.

\section{Promovendo o imaginário da Nação e legitimando o homem cordial: os livros didáticos como lugares de memória}

Perspectiva eficazmente transposta ao sistema educacional, a cordialidade -e, portanto, as novas formas de pensar a formação do corpo social brasileirodetivera importante difusão através da circulação dos livros didáticos. Correspondendo ao material didático mais empregado nas escolas, tradicionalmente intrínseco à história ensinada e norteador do trabalho docente, tais materiais se posicionaram, inabalavelmente, como ferramentas centrais ao desenvolvimento das práticas pedagógicas ${ }^{27}$-posição esta, eminentemente, importante à veiculação dos aspectos delineadores do caráter nacional.

De um modo geral, prestando a tais intentos desde o século XIX, a função social dos manuais escolares sempre fora, dentre outras, legitimar o despertar de um amor à Pátria; um sentimento de pertencimento àquela Nação, ou seja, uma identidade nacional -que, em nosso caso, se dispunha a explicar o que era o Brasil e o que significava ser brasileiro ${ }^{28}$.

A construção de uma identidade nacional percorreu os caminhos dos livros escolares e das salas de aula: sob a orientação dos professores, os textos didáticos ensinavam a nação aos brasileiros. No entanto, o projeto de construção da identidade nacional no singular teve que abrir espaço para a pluralidade e a diferença: um capítulo dessa história desenrolou-se nos livros didáticos ${ }^{29}$.

Frente a estas considerações, torna-se claro o motivo pelo qual diversas intencionalidades incidiram -e incidem-, a todo o momento, sobre o proces-

26. Sobre essa discussão, vale a pena as reflexões traçadas por Marcos Chor Maio, Ver em: Chor Maio, M., "O projeto Unesco e a agenda das ciências sociais no Brasil nos anos 40 e 50". Revista Brasileira de Ciências Sociais 14 (41) (1999), p. 143. http://doi.org/10.1590/S010269091999000300009.

27. Rodrigo da Silva, J. "Itinerários do livro didático como objeto central no ensino de História". Antíteses 6 (2013), pp. 103-125.

28. A referida colocação diz respeito à importância de se atribuir significado à identidade -individual ou coletiva- e, nessa lógica, são válidas as ponderações construídas por Tzevtan Todorov, afinal, “(...) os homens, assim como os grupos, vivem no meio de outros homens, de outros grupos, e por isso não basta afirmar que cada um tem o direito de existir; também é preciso ver como essa defesa de si influi sobre a existência dos outros". (Todorov, T. "Memória do Mal, Tentação do Bem: indagações sobre o século XX". São Paulo 2002, p. 195).

29. Medeiros Gasparello, A., "Construtores de identidades: a pedagogia da Nação nos livros didáticos da escola secundária brasileira". São Paulo 2004, p. 18. 
so constitutivo destas ferramentas pedagógicas, determinando como uma "(...) realidade social é construída, pensada, dada a ler ${ }^{30 \prime}$. Neste sentido, os livros didáticos correspondem, terminantemente, a objetos de cultura indispensáveis à compreensão dos conflitos estabelecidos no campo sociocultural -uma vez que suas abordagens resultam das disputas de narrativas que visam legitimar determinadas práticas a serem desencadeadas no convívio social. Por sua vez, interpretando estas narrativas como representações que deflagram o processo de significação do real ${ }^{31}$, deve-se salientar que tais discursos foram- e ainda o são -produzidos por certos sujeitos que, inseridos num lugar de poder, intentam ratificar sua visão de mundo.

A autenticação destes prismas -que objetivam atribuir sentidos às relações sociais-, fundamenta-se, sobretudo, na evocação do passado, mobilizando certas memórias que, como bem lembrara Tzevtan Todorov, contribuem "(...) tanto para a constituição da identidade, individual ou coletiva, quanto para a formação de nossos valores, ideais e princípios (... $)^{32 "}$. "A serviço do interesse ${ }^{33 ",}$ a recordação leva em conta certa fidelidade em relação ao passado, tal como uma utilidade perante o presente ${ }^{34}$.

Nesse sentido, vale pontuar que a necessidade de conjurar a memória como modo de reafirmação no tempo presente torna-se, decerto, justificável ${ }^{35}$. Essa apologia em favor das práticas de evocação do passado resulta, inclusive, naquilo que Pierre Nora cunhara como lugares de memória. Inscrevendo os acontecimentos na memória e, ao mesmo tempo, criados a partir do que já se está escrito nela, estes "(...) lugares são com efeito nos três sentidos da palavra, material, simbólico e funcional, simultaneamente, somente em graus diversos ${ }^{36 "}$. Constituídos por "um jogo da memória e da história"37, estes locais detêm a pretensão pedagógica de se fazer lembrar determinadas circunstâncias e, igualmente, enraizar tais lembranças no imaginário social.

30. Chartier, R. "A história cultural entre práticas e representações". Lisboa 2002, p. 17.

31. As representações do mundo social assim construídas, embora aspirem à universalidade de um diagnóstico fundado na razão, são sempre determinadas pelos interesses de grupo que as forjam. Daí, para cada caso, o necessário relacionamento dos discursos proferidos com a posição de quem os utiliza.

32. Todorov, T. "Memória do Mal, Tentação do Bem: indagações sobre o século XX". São Paulo 2002, p. 207.

33. Ibid., p. 195.

34. Ibid., p. 234.

35. Afinal, "(...) sem um sentimento de identidade que nos pertença, vemo-nos ameaçados em nosso próprio ser e paralisados. Tal exigência de identidade é perfeitamente legítima: o indivíduo precisa saber quem é e a que grupo pertence". (Ibid., p. 195).

36. Nora, P., "Entre memória e história: a problemática dos lugares". Projeto História 10 (1993), p. 21. Disponível em: https://revistas.pucsp.br/revph/article/view/12101/8763. (Acesso em: 19 abr. 2019).

37. Ibid., p. 21. 
Entretanto, é válido pontuar que, no mais das vezes, os apelos em favor do dever de memória apontam, conforme argumentara Todorov,

...a defesa de uma seleção de fatos dentre outros, aquela que garanta aos seus protagonistas a manterem-se no papel de herói, de vítima ou de moralizador, por oposição a qualquer outra seleção que ameace atribuir-Ihes outros papéis menos gratificantes ${ }^{38}$.

Ainda, porém, faz-se imprescindível destacar que este processo de reminiscência do passado necessita, eventualmente, considerar certos recursos que permitam a prática do esquecimento -afinal, a lembrança é importante, mas quando em seu estado excessivo, pode tornar-se perigosa ao bem-estar público $^{39}$.

Nessas condições, pode-se dizer que a construção da identidade nacional brasileira projeta-se nos liames entre a lembrança e o esquecimento; a necessidade de mostrar a quem devemos nos orgulhar e a conveniência de se ter apaziguados os nítidos conflitos sociais; o dever de nos convencer que somos uma sociedade de homens cordiais e, ao mesmo tempo, omitir a violência profundamente visceral característica de nosso processo histórico. Entre a lembrança e sua ausência, a brasilidade é construída e legitimada, profundamente pautada por seus antagonismos.

Consequentemente, ao considerarmos a posição dos manuais escolares diante os mecanismos de promoção da identidade brasileira, não seria demais perceber que os mesmos são constituídos seguindo a mesma lógica. Ainda que marcados por uma seleção de testemunhos que priorizem o esquecimento de determinados aspectos do passado, estes materiais atuam como importantes lugares de memória, uma vez que assumem uma materialidade em que se faz promover uma memória social; detém uma função pedagógica -seja em relação ao seu sentido didático-escolar ou em sua acepção nas relações cotidianas- e possuem, ainda, um caráter simbólico -atribuindo valor aos testemunhos que pretendem educar.

\section{O lugar do Brasil nos livros didáticos de Joaquim Silva}

Escritos por Joaquim Silva, os livros História do Brasil: para a primeira série do ginasial e História da América para a segunda série do ginasial carregam consigo aspectos de grande relevância à compreensão das considerações até aqui traçadas. Organizadas e patenteadas pela Companhia Editora Nacional,

38. Todorov, T. "Memória do Mal, Tentação do Bem: indagações sobre o século XX". São Paulo 2002, p. 206.

39. Ibid., p. 199. 
estas obras fizeram parte da formação escolar de um grande número de indivíduos.

Apresentando estreita relação com uma historiografia "tradicional" -que, corresponderia a uma abordagem historiográfica com narrativas que apontam a sujeitos e momentos históricos consagrados ${ }^{40}$ - a obra em questão indica, em suas estruturas discursivas, um tratamento de caráter acontecimental aos conteúdos que se propõe a mobilizar ${ }^{41}$, bem como uma transmissão dos conhecimentos instituídos pautados por um paradigma informativo ${ }^{42}$.

Para além de seus aspectos didático-pedagógicos, ao debruçar-se sobre as narrativas construídas pelo autor, torna-se perceptível as pretensões ligadas à construção de um determinado projeto de identidade brasileira -tomando a cordialidade como aspecto básico e delineador de nossa índole desde o período colonial. Isso se justifica, por sua vez, graças ao emprego de termos que aludem às características do homem cordial como, por exemplo, "harmonizar"; "pacificação"; "cordial"; "benevolência"; dentre outros.

Tomemos como exemplo as considerações tecidas a respeito da colonização empregada pelos portugueses. Desde a chegada lusitana, o contato com determinadas comunidades indígenas -bem como o estabelecimento de suas relações- se apresentara de modo pacífico:

Pero Vaz de Caminha refere em sua carta famosa como foi pacífico, mesmo cordial, o primeiro encontro dos íncolas com os portuguêses: desconfiados assustadiços quando os viram, mostraram-se logo mais confiantes; e, no terceiro dia após o descobrimento, ajudaram os lusita-

40. Nas considerações de Sônia Regina Miranda e Tânia Regina de Luca, esta história tradicional "(...) aborda a História em sua dimensão meramente informativa e não valoriza o conhecimento histórico em seu aspecto construtivo. As narrativas são organizadas a partir de recortes já consagrados, as fontes históricas ganham caráter mais ilustrativo e não são exploradas numa dimensão que aproxime o aluno daquilo que preside o procedimento histórico; nesse sentido, uma concepção de verdade pronta e irrefutável preside a obra". Regina Miranda, S. y Regina de Luca, T. "O livro didático de história hoje: um panorama a partir do PNLD". Revista Brasileira de História 24 (2004), p. 140. Disponível em: http://www.scielo.br/pdf/rbh/ v24n48/a06v24n48.pdf. (Acesso em: 14 abr. 2018).

41. Ainda tomando como referência Tânia Regina de Luca e Sônia Regina Miranda, temse que esta modalidade de interpelação dos assuntos se caracteriza "(...) por uma visão mais informativa acerca da narrativa (...) e que, nesse sentido, prioriza aquela dimensão que Vilar nos aponta como 'conhecimento de uma matéria'". (Ibid., p. 135).

42. Sobre esta categorização, entende-se que "(...) os objetivos educacionais selecionados centram-se na obtenção da informação e do conteúdo histórico, independentemente de como tal conteúdo é processado pelo aluno sob o ponto de vista cognitivo; nesse sentido, o diálogo com os saberes dos estudantes, ou mesmo a proposição de situações cognitivas que possam gerar o entendimento por meio da comparação de tempos e/ou circunstâncias, é praticamente nulo". (Ibid., p. 137). 
nos a renovar a provisão de suas naus, em troca de barretes vermelhos ou de fios de $\operatorname{contas}^{43}$ (negrito meu).

Mais a diante, discorrendo sobre os aspectos do trabalho escravo, o autor apresentara a "índole benévola da maioria dos senhores" que, inseridos na lógica escravista, "(...) seriam, em sua maioria, menos desumanos que os da África ou dos 'tumbeiros ${ }^{44 "}$. Dentre tantos aspectos de suas qualidades, o autor aponta, por exemplo:

Costumes belíssimos instituem-se entre os senhores; como o de apadrinhar os remissos ou fugitivos, o que impede o castigo e nenhum senhor viola. O costume de ceder um dia ou dois (sábado e domingo) ao trabalho do negro é mais tarde confirmado por lei (1700) e também o reconhecimento da propriedade privada do escravo. Outro costume é o de alforrias na pia, o que se fazia com uma espórtula insignificante (de 5 a 50 mil réis), que nunca era recusada; esse hábito era freqüente, sobretudo quando as crianças traziam a pele mais clara ${ }^{45}$.

Posteriormente, nas representações construídas sobre o Brasil-Império, o autor trouxera à tona outras circunstâncias que apontavam este nosso suposto caráter capital. Atentando-se tanto às relações internas quanto às atuações diplomáticas ${ }^{46}$, Joaquim Silva apresentara personagens históricos que se consagrariam pela índole altruísta, como no caso de D. Pedro II que procurou, frente à Guerra dos Farrapos e à Balaiada, "(...) acalmar os ódios por um decreto de anistia $(. . .)^{47 \prime \prime}$, conseguindo a pacificação. Em um período demarcado, portanto, por homens cordiais, o autor apontara outras figuras como José Araújo Ribeiro -“(...) que era prudente e conciliador (... $)^{48 " ;}$ ou, até mesmo, o Duque de Caxias, cuja personalidade é profundamente pautada pelo patriotismo e espírito de reconciliação ${ }^{49}$.

43. Silva, J., "História do Brasil: para a primeira série do ginasial". São Paulo 1956, pp. $32-33$.

44. Ibid., p. 52.

45. Ibid., p. 52. Sobre as relações senhor-escravo, no Brasil colonial, o autor evidencia também que "Nas colônias inglêsas, ao contrário do que acontecia no Brasil e nas colônias espanholas, o elemento negro conservou-se isolado, como ainda hoje se observa nos estados delas originados". (Ibid., p. 54).

46. Joaquim Silva destaca: "A política exterior do Brasil tem se norteado de acôrdo com suas tradições pacíficas. A lei magna do país, desde 1891, consigna o recurso ao arbitramento para a solução de questões internacionais e repulsa a tôda guerra de conquista". (Idem. "História da América: para a segunda série do ginasial". São Paulo 1954, p. 112).

47. Idem, op. cit., 1956, p. 150.

48. Ibid., p. 151.

49. Apenas para citar um exemplo sobre as representações sobre Duque de Caxias: "Ante a gravidade da situação recorre o imperador ao patriotismo de Caxias para pacificar a provín- 
Fato curioso, diante tais considerações, está nas narrativas acerca dos diversos embates militares travados entre o Brasil e outros Estados da América Latina, como se faz perceber nas querelas assistidas na região do Prata:

O império todavia teve, em seus primeiros anos, de intervir militarmente em questões que agitaram a região do Prata: forçaram a tal atitude remanescentes de conflitos da época colonial, lutas partidárias e outras que causavam depredações e mortes nas terras do Rio Grande do Sul, freqüentemente invadidas, além da defesa de nossos incontestáveis interêsses no Prata e, por isso mesmo, zelar pela independência uruguaia. ${ }^{50}$

Note, com o exemplo acima, que a ideia de que o Brasil fora "forçado" a desencadear um conflito armado por ter sido vítima das ações de outros Estados Nacionais corrobora à noção de nossa cordialidade e justifica, dessa forma, a violência característica de nossa história. Nesse bojo, outro exemplo observado é apresentado em:

Fomos também forçados a prolongada guerra contra o govêrno do Paraguai que injustamente nos agredira invadindo o sul de Mato Grosso e o Rio Grande do Sul: e dessa campanha, que custou enormes sacrifícios nada ganhámos, tendo o Brasil perdoado aos vencidos a própria dívida de guerra. ${ }^{51}$

Ainda, para citar situação análoga, tem-se:

Rosas interveio na luta em favor de Oribe; mas o Brasil, que não era atendido nos seus protestos contra as depredações que faziam os 'Blan$\cos ^{\prime}$ no Rio Grande, foi forçado a intervir na luta ${ }^{52}$.

Características desenvolvidas no decorrer da colonização, com uma significativa evidência ao longo do regime imperial, as narrativas sobre as "entradas forçadas" e as políticas de arbitramento se fazem expressivas, também, no que diz respeito às abordagens do período republicano -afinal, "(...) a prática do arbitramento era, entretanto, seguida no Brasil desde muitos anos: as nossas questões de fronteira nunca foram resolvidas pela fôrça, mas pelo arbitramento ou por acôrdos diretos $(. . .)^{53 \prime \prime}$. Assim, verifica-se, a título de exemplo, que:

cia revoltada. O grande militar alcança várias vitórias e consegue a volta de Bento Manual às fileiras legais. Exorta sem êxito os adversários à reconciliação (...)". Ibid., p. 151.

50. Idem, "História da América: para a segunda série do ginasial". São Paulo 1954, p. 112.

51. Ibid., p. 112.

52. Idem, "História do Brasil: para a primeira série do ginasial". São Paulo 1956, p. 155.

53. Idem, op. cit., 1954, pp. 138-139. 
O sétimo quatriênio constitucional foi o do Dr. Venceslau Braz Pereira Gomes que governou na difícil fase da primeira Grande Guerra. Ainda assim, conseguiu melhorar a situação financeira. O Brasil teve de participar da conflagração, enviando uma esquadrilha de nossa marinha para cooperar com os aliados no policiamento do Atlântico ${ }^{54}$. (grifo meu)

E, nesta mesma estrutura narrativa, faz-se possível observar que "(...) o torpedeamento de cinco navios brasileiros pelos alemães levou o Brasil a entrar no conflito ${ }^{5 \prime \prime}$-mas, não sem estabelecer, logo em seguida, sua benevolência através dos tratados cordiais:

Entretanto, resolveram-se por arbitramento ou acôrdos, quase todas graças ao gênio e patriotismo do Barão do Rio Branco, as nossas questões de limites. A política exterior do Brasil não se desviou de seu ideal de concórdia, fiel aos princípios da boa vizinhança entre as nações da América e cooperando para a paz do mundo ${ }^{56}$.

Em vistas destas exemplificações, se tornam claras as configurações dos discursos que apontavam as representações da história brasileira. Aspecto que permearia a mentalidade social, a lógica da cordialidade encontraria nos manuais escolares formas eficazes de difusão, formando a ideia de que, de fato, demos ao mundo o homem cordial.

\section{Considerações finais}

Tendo em mente as reflexões até aqui construídas, as investigações empreendidas buscaram traçar alguns aspectos acerca da construção da identidade nacional brasileira -destacando-se a preocupação de seus idealizadores em desenvolver estratégias que pudessem legitimar a união do povo. Nesse sentido, atentando-nos aos esforços empregados na formação da brasilidade a partir da década de 1930, fora essencial debruçarmos sobre o conceito de homem cordial. Concepção cunhada por Ribeiro Couto, a cordialidade viria adquirir posição privilegiada no projeto nacionalista de nosso país, protagonizando os estudos de intelectuais que, decerto, corroboraram á formação de um imaginário sobre a sociedade brasileira- destacando-se, aqui, as figuras de Gilberto Freyre e Sérgio Buarque de Holanda.

Levando-se em consideração o fato de os livros didáticos estarem intrinsecamente ligados às pretensões de consolidação do sentimento nacionalista - desde seu surgimento no século XIX-, estes materiais consistiram em eficazes veículos

54. Idem, op. cit., 1956, p. 196.

55. Ibid., p. 196.

56. Idem, "História da América: para a segunda série do ginasial". São Paulo 1954, p. 112. 
de difusão dos valores nacionalistas -e, nessa lógica, considerando-se o caso do Brasil, a divulgação de nossa suposta cordialidade. Carregando consigo certas representações da realidade histórica de nosso país, os manuais escolares buscaram fundamentar uma perspectiva harmônica e isenta de conflitos sociaisratificando nossa cultura e, portanto, orientando nossas práticas.

Mobilizando certas memórias, os manuais escolares -sobretudo, os de história- se constituem como fontes indispensáveis à compreensão do processo de evocação do passado -apontando, dentre outros aspectos, as intencionalidades que orquestram a formação da identidade, conformada entre a lembrança e o esquecimento, com vistas a legitimar um modelo de bem-estar social. Eis, portanto, o livro didático; eis, portanto, um lugar de memória.

\section{Referências bibliográficas}

Bourdieu, P., "Algumas propriedades dos campos", P. Bourdieu, Questões de sociologia. Rio de Janeiro 1983.

Buarque de Holanda, S., Raízes do Brasil. São Paulo 2014.

Chartier, R., A história cultural entre práticas e representações, Lisboa 2002.

Chor Maio, M., "O projeto Unesco e a agenda das ciências sociais no Brasil nos anos 40 e 50", Revista Brasileira de Ciências Sociais 14 (41) (1999), pp. 141158. http://doi.org/10.1590/S0102-69091999000300009.

Freyre, G., Casa Grande \& Senzala: introdução à história da sociedade patriarcal no Brasil. Rio de Janeiro 1995.

Medeiros Gasparello, A., Construtores de identidades: a pedagogia da Nação nos livros didáticos da escola secundária brasileira. São Paulo 2004.

Nora, P., "Entre memória e história: a problemática dos lugares", Projeto História 10 (1993). Disponível em: https://revistas.pucsp.br/revph/article/ view/12101/8763. (Acesso em: 19 abr. 2019).

Ortiz, R., Cultura Brasileira e Identidade Nacional. São Paulo 1985.

Regina Miranda, S. y Regina de Luca, T. "O livro didático de história hoje: um panorama a partir do PNLD", Revista Brasileira de História 24 (2004), pp. 123-144. Disponível em: http://www.scielo.br/pdf/rbh/v24n48/a06v24n48. pdf. (Acesso em: 14 abr. 2018).

Silva, J. História da América: para a segunda série do ginasial. São Paulo 1954.

Silva, J. História do Brasil: para a primeira série do ginasial. São Paulo 1956.

Todorov, T. Memória do Mal, Tentação do Bem: indagações sobre o século XX. São Paulo 2002. 